\title{
NSU
}

Florida

NOVA SOUTHEASTERN

UNIVERSITY

Nova Southeastern University

NSUWorks

College of Psychology: Faculty Articles

College of Psychology

9-1-1989

\section{Moratorium on Maltzman: an Appeal to Reason}

Mark B. Sobell

Nova Southeastern University, sobellm@nova.edu

Linda C. Sobell

Nova Southeastern University, sobell1@nova.edu

Follow this and additional works at: https://nsuworks.nova.edu/cps_facarticles

Part of the Psychology Commons

\section{NSUWorks Citation}

Sobell, M. B., Sobell, L. C. (1989). Moratorium on Maltzman: an Appeal to Reason. Journal of Studies on Alcohol, 50(5), 473-480. Available at: https://nsuworks.nova.edu/cps_facarticles/694

This Article is brought to you for free and open access by the College of Psychology at NSUWorks. It has been accepted for inclusion in College of Psychology: Faculty Articles by an authorized administrator of NSUWorks. For more information, please contact nsuworks@nova.edu. 


\title{
Moratorium on Maltzman: An Appeal to Reason*
}

\author{
MARK B. SOBELL† AND LINDA C. SOBELL $\dagger$ \\ Clinical Institute, Addiction Research Foundation, 33 Russell Street, \\ Toronto, Ontario M5S 2S1, Canada
}

\begin{abstract}
Maltzman's comment on Cook (1985), which appears elsewhere in this issue, is an unveiled attempt to resurrect the same allegations about our research that he made 7 years ago. None of the allegations are new! Over the past 7 years, those allegations have been the topic of 5 separate inquiries, in each of which we were vindicated. In this response, we review the multiple inquiries and we show how Maltzman continues to (1) cite our work out of context, (2) make false assumptions about the inquiries and our procedures
\end{abstract}

and (3) disregard evidence contradicting his assertions. He relies on data that, to use his characterization, are a "tempest in a teapot." Having answered the same fundamental attack time and again over the past 7 years, we declare a unilateral moratorium on responding to Maltzman. Moreover, our repeated vindications, and research published over the last 20 years corroborating moderation outcomes, illustrate that, indeed, science is self-correcting. (J. Stud. Alcohol 50: 473-480, 1989)
Truth is generally the best vindication against slander. -Abraham Lincoln, 1864

$\mathrm{S}^{\mathrm{E}}$ EVEN YEARS AGO, Pendery, Maltzman and West (1982) publicly attacked our study "Individualized Behavior Therapy for Alcoholics (IBTA)" (Sobell and Sobell, 1973). The study itself was conducted nearly 20 years ago. Nevertheless, we find it necessary to comment on Maltzman's article, "A Reply to Cook, "Craftsman versus Professional: Analysis of the Controlled Drinking Controversy" (see pp. 466-472 in this issue). At the beginning, it is critical for readers to understand that none of the allegations or suggestions about the study procedures that can be inferred from Maltzman's article are new; all have been addressed in previous inquiries.

At the outset, to appreciate the enormity and magnitude of the attack and the multiple investigations, we ask readers as they proceed through our response to try and imagine themselves in our place: obliged to address the same well-worn allegations after having been vindicated in five separate inquiries.

\section{Seven Years of Questions, but Nothing New!}

We have put up with years of the most intense and detailed scrutiny ever imposed on researchers in the alcohol field, and inquiry after inquiry has vindicated

* The views expressed herein are those of the authors and do not necessarily reflect those of the Addiction Research Foundation.

$\dagger$ The authors are also affiliated with the Departments of Psychology and Behavioural Science, University of Toronto. our conduct of the study. A short history of the multiple inquiries into the conduct of the IBTA study is of relevance because of the offhanded way some of the inquiries are referred to by Maltzman.

The initial inquiry, which came to be known as the Dickens Committee inquiry, was established at our request by the Addiction Research Foundation. Four highly distinguished senior individuals respected for their integrity and who were not involved in the alcohol field were given the charge of investigating multiple allegations that we had engaged in scientific misconduct in our performance and reporting of the IBTA study (in his article, Maltzman refers to several of the allegations investigated by the Dickens Committee). The committee was chaired by Bernard Dickens, Ph.D., LL.D., professor of law, preventive medicine and biostatistics, criminology and community health at the University of Toronto, an internationally recognized expert in medical jurisprudence. The other members were: Harold Warwick, M.D., professor emeritus and former vice-president of health sciences at the University of Western Ontario; Anthony Doob, Ph.D., director of the Centre of Criminology at the University of Toronto; and William Winegard, Ph.D., chairman of the Council of Ontario Universities, former president and vicechancellor of the University of Guelph, and presently a member of the Canadian Parliament and minister of state for science and technology.

The committee, at its first meeting with us, informed us that from its perspective, from that time forward, they would consider us guilty until such time as we could convince them the allegations were unfounded. 
The committee spent 5 months conducting its investigation, met with us very frequently and had complete access to our massive amount of original records (see Dickens et al., 1982; Doob, 1984; Sobell and Sobell, 1984a). The main conclusion of their 123-page report was: "The Committee finds there to be no reasonable cause to doubt the scientific or personal integrity of either Dr. Mark Sobell or Dr. Linda Sobell"' (Dickens et al., 1982, p. 109).

Maltzman would incorrectly have readers believe that the committee was somehow hoodwinked into tabulating follow-up contacts by counting listings in a telephone log and not even bothering to compare the original raw data with published data and to crosscheck information when possible. Readers need only examine the Dickens Committee Report for themselves to become convinced Maltzman has apparently misread the committee's report. In the report the committee describes evaluating in detail the totality of records available for research subjects selected at random, describes the wealth of records reviewed over the course of their investigation and clearly states that the telephone logs were only maintained for the second year of follow-up (Dickens et al., 1982, see p. 83). Obviously, therefore, Maltzman's claim that the committee used the logs as the sole data source for their table of first and second-year follow-up contacts is in error. In fact, the committee used the original raw follow-up data as their primary data source for counting the follow-up contacts; the telephone logs were used to cross-check notes in the data files for the second year of follow-up.

Immediately following the release of the Dickens Committee's findings, the conduct of the IBTA study was further scrutinized by an investigator from the United States Congress. The investigator had complete access to our data. As reported in the APA Monitor:

James Jensen, of the House Science and Technology Committee's subcommittee on investigations and oversight, was making a preliminary inquiry into allegations of fraud in Sobell study, conducted in 1971-72, to determine whether a full-fledged investigation by the subcommittee was warranted.

Unlike a Canadian committee that investigated the charges last fall, "I just waded into the data" rather than first identifying specific questions to be answered," he said. In investigating other alleged scientific frauds, he said, he has found that false data "don't hold up for a minute" when the scientist is asked for original materials. The Sobells had an entire safe full of tapes and records, including "documents from the patients' own hand." (Fisher, 1983, p. 48)

In a letter sent to us on March 23, 1983, conveying his findings, Mr. Jensen wrote: "Based upon my review of the evidence, I have concluded that there is no evidence to support the allegation that your study was based upon fallacious, falsified or otherwise invented data. The correlation between your notes of contacts with patients, your phone logs and the tape recordings of those contacts have convinced me that your report of the study was made in good faith."

The third investigation took nearly one and one-half years, culminating in August 1984 with the release of what Maltzman refers to as the Trachtenberg Report (Trachtenberg, 1984). That report described the investigation conducted by the Alcohol, Drug Abuse and Mental Health Administration (ADAMHA), with the assistance of the Division of Management Survey and Review at the National Institutes of Health; the investigative team included two research psychiatrists. On two occasions, the team members met with us, "during which time they had free access to the Sobells' data" (Trachtenberg, 1984, p. 2). For complex reasons discussed in their report (Trachtenberg, 1984), the investigation was limited in various ways. Nevertheless, they concluded: "Based on the investigative team's necessarily limited review, the Steering Group [to whom the team reported] did not find evidence to demonstrate fabrication or falsification of data reported by the Sobells" (p. 2).

An important part of the ADAMHA investigation was that one of the patients in the study who had made allegations about its conduct "presented some background information on several patients and made available some related documents [to the investigators]. These included lists of medical records, arrest records, correspondence, and affidavits" (Trachtenberg, 1984, p. 16). The ADAMHA report concluded: "In general, the investigative team found that [the subjects'] documentation of rehospitalizations, arrests for excessive drinking, etc. did not contradict the outcomes reported by the Sobells" (Trachtenberg, 1984, p. 25). In other words, the reports and records provided to the investigators by former patients did not contradict the data we used to report treatment outcomes approximately a decade earlier.

Following on the heels of the Trachtenberg Report was an investigation conducted by the Ethics Committee of the American Psychological Association based on a complaint submitted by Maltzman. According to the Ethics Committee: "The specific charges refer to: (1) your alleged failure to apprise readers of your use of the time-line follow-back method in your earlier publications; and (2) the accuracy of your published reports relating to your follow-up interviews." $\mathrm{We}$ were informed of the following Ethics Committee decisions based on their "careful investigation of the charges against you raised by Dr. Irving Maltzman's complaint." With regard to the first charge, they reported: 
Our adjudications on this issue are as follows: (1) although your description of this method could have been more clearly worded in your initial publications, and that such clarification would have been helpful to readers, we did not find these descriptions to be inaccurate, per se; (2) we did not find evidence to sustain a charge that the failure to clarify the methodology further was the result of an intent to misrepresent your methodology to the readers.

Regarding the second charge, the Ethics Committee reported: "There was no convincing evidence that your admittedly erroneous estimates of the frequency of follow-up contacts significantly affected the conclusions drawn from this research." Despite these findings, of which Maltzman was sent a copy, he repeats these charges in his present article.

Finally, beginning in 1983, concurrent with these latter investigations and outliving them, we were named as plaintiffs in a $\$ 96$ million lawsuit filed by some former subjects and their collaterals in the Superior Court of California. On December 17, 1987, more than 4 years after it was filed, the suit was finally dismissed. In the notice of dismissal, the judge cited several bases for his actions, including, "That plaintiffs' complaint was uncertain as a whole." 2 Further, in a recent article in the U.S. Journal of Drug and Alcohol Dependence, which mentioned the dismissal of the suit, Harold Scolinos, the attorney for the plaintiffs, was quoted as saying: "The court felt that there was no damage to the plaintiffs caused by negligence or fraud" (Meacham, 1989, p. 10).

Having now spent 7 years dealing with these same allegations, and having repeatedly been vindicated, there is no need to address each and every allegation here. Rather, we will address a few of the issues Maltzman raises in order to cast the controversy in perspective and to set the record straight on some matters.

\section{The Type of Follow-Up Data Collected}

In his present article, as in his ethics complaint against us filed with the American Psychological Association (APA), Maltzman claims we could not have gathered drinking disposition follow-up data in the manner reported. He asserts that we did not describe the time-line procedure in our reports. As noted by the APA, however, the published description of our data gathering procedures was accurate. We have also discussed elsewhere (Sobell and Sobell, 1984a) that "at the time, we did not apply a name to the method, but merely considered it a necessary procedure for the collection of daily drinking disposition data" (p. 164). This is supported by Timothy Baker's comments, published in this issue (pp. 481-483) of the Journal.

As his main support for his contention, Maltzman presents a fundamentally irrelevant quotation taken from an article we published in 1979. This exemplifies a feature of Maltzman's writing that we have noted on other occasions (Sobell and Sobell, 1984a,b,c). In the abstract to his article (this issue), Maltzman states that we "have made mutually contradictory claims concerning the procedures employed." Later in his article, he quotes from our 1979 article (Sobell et al., 1979) where we reported reliability findings for the time-line follow-back procedure. He states: "It is noteworthy that in 1979 we are cautioned against using the timeline follow-back method with gamma alcoholics, the type of patient employed in the IBTA study. But the Dickens Report and the Sobells (1984) now claim that gamma alcoholics were interviewed by the time-line follow-back method as early as 1972. Both assertions cannot be right, and the apparent inconsistency is never explained."

By way of explaining what Maltzman alleges to be an "apparent inconsistency," and also to illustrate how he continues to cite our work out of context, the following excerpt is presented from a letter sent to Maltzman over a year ago (April 7, 1988) by a journal (not $J S A$ ) editor (a copy of this letter was sent to us by the editor). The importance of this letter is twofold: it addresses the same allegation raised by Maltzman in his present article and it shows that Maltzman is aware of our position but still cites our work out of context. In this regard, the editor wrote to Maltzman: "I enclose, with permission from Mark and Linda Sobell, photostats of passages in which they comment on your text." The passages relevant to the time-line:

Yet, Maltzman quotes only from a 1979 article of ours which investigated the "test-retest reliability" of the timeline with problem drinkers. In that very brief article we did refer to the method as "newly developed," meaning that it was a relatively recent advance as compared with other measures of treatment outcome that had been used for decades. Dr. Maltzman then goes on to quote and emphasize our statement that "these results cannot yet be generalized to chronic alcoholics." He then states, "We are now cautioned against using the time-line follow-back method with the very type of patient employed in the earlier Patton study. ..." This is a clear case of our being quoted out of context. The study quoted was a test of the reliability of the time-line method, and the results which we cautioned should not be generalized were those for "reliability." We did not caution against using the method with chronics; we did caution against generalizing our results regarding reliability. Use of a method, and establishing psychometric characteristics of a method, are quite separate issues, as demonstrated by the fact that the quantity-frequency method of obtaining drinking data was used for many years before any studies of its psychometric properties were undertaken.

He [also] fails to note that in the same year that the reliability study he cited was published, we also published 
on the reliability of the method with chronics (Maisto et al., 1979) and the subsequent year on its validity with chronics (Cooper et al., 1980).

Readers familiar with the time-line literature will know that what is stated in the above excerpt is correct. We are at a loss, though, to explain how Maltzman could have misunderstood our caution against generalizing the reliability findings as meaning that the method, itself, should not be used at all.

Maltzman also expresses incredulity that not until the course of the Dickens Committee's investigation were we aware that the actual mean number of contacts with subjects (15.7 as calculated by the Dickens Committee) was fewer than the minimum 24 contacts our description of procedures would have led readers to expect. We have addressed this issue in some detail elsewhere but shall recount the major points here. First, the statement in our original publications that all subjects were contacted every 3 to 4 weeks was plainly and simply in error, as determined by the Dickens Committee and as we have acknowledged elsewhere (Sobell and Sobell, 1984a,b). It certainly was not intentional, for even in the same publications where the statement appears (Sobell and Sobell, 1976, 1978) we discussed several cases where follow-up contacts could not be made for some time due to difficulty in locating subjects. Clearly we could not have contacted all subjects so regularly while also losing contact with some subjects for extended periods.

Nearly 20 years ago, when the research was conducted, we had no computerized record keeping and for a considerable part of the follow-up interval we had no help or support. On our own time, we gathered follow-up data from 70 patients and their collateral information sources. Since it often took multiple attempts to contact subjects and their collaterals, a great number of attempts took place each month, and collecting follow-up data seemed a never ending process. This is not to excuse the overstatement that appeared in our publications, but only to set the context for considering Maltzman's argument. Confronted, as we were, with the allegation that we had not contacted subjects as frequently as we had claimed, at first we were astonished that we had ever made the claim since we had at the same time discussed our difficulties in locating some subjects. The allegation by Pendery et al. was not just that we had contacted subjects less frequently than we had reported, however, but that we had contacted the vast majority of subjects only one to four times during the entire follow-up period (Dickens et al., 1982, p. 75). This, we knew, could easily be proven to be absurd. For that reason, we had not done a painstaking tabulation of actual contacts prior to the tabulation performed by the Dickens Com- mittee. We expected that the committee's tabulation would be somewhat lower than what we had claimed, given that we had reported that some subjects were difficult to locate at times, but we also knew the allegation that we had contacted subjects no more than four times would clearly be proven wrong. As it turned out, of course, we were shocked to find that the count by the Dickens Committee was below our expectations. There is no way to relive the moment when we were with the committee counting contacts and realized what had happened, and no amount of incredulity expressed by Maltzman can change that fact.

Before leaving this topic, there is an important postscript. When the Dickens Committee's report was released, we learned that "Pendery et al. no longer stand behind their Draft estimates of follow-up ... but claim that only 'an intermediate number' of followup contacts were made" (p. 75). This was a staggering revelation, since Pendery et al.'s original allegation was supposedly based on subjects' affidavits, and therefore their database for the allegation presumably would not have changed.

\section{Tempests and Teapots}

Elsewhere, Maltzman has stated, "Our evidence is not simply based upon the verbal reports of these patients. If that's all we had, it would be a tempest in a teapot" (Fisher, 1982). Yet, it is clear from Maltzman's article that the main evidence that he claims refutes our findings consists of chronic alcoholics' extremely long-term recollections, obtained by unreported procedures.

There are two major difficulties in attempting to respond to Maltzman's allegations about the IBTA study. First, no detailed description of his data gathering procedures has ever been published. The total information that has ever been reported about the procedures used by Pendery et al. (1982) is that they "completed an independent clinical follow-up" of the subjects (p. 170, italics added), and that they "located and interviewed as many as possible of the original subjects" (p. 172). Second, no actual outcome data have been published by Maltzman to challenge our findings. Pendery et al. (1982) published excerpts from hospital records, but these have never been claimed to contradict our data. Beyond that, their reports were limited to anecdotes and to global summary statements of outcomes, most of which referred to time periods after our follow-up had already been completed. In contrast to Maltzman and his colleagues' nonquantitative "tidbits" of data, the inquiries into the conduct of the IBTA study had available to them for scrutiny all of our original research records and raw data. Since the scientific community knows so little about Maltzman's 
procedures and since he fails to present his findings in a quantified fashion, all we can respond to are the subjects' distant verbal recountings, in the form of affidavits, which form the major basis upon which Maltzman questions our data.

Prior to Maltzman's present article we had seen only one subject's affidavit (Subject CD-E 1 as referred to by Pendery et al., 1982), an affidavit that was evaluated by the Dickens Committee. That affidavit was a very important one, however, for it was the sworn deposition of a subject who played a key role in the Pendery et al. investigation. Subject CD-E 1 is acknowledged in the Pendery et al. (1982) article as primary "among the many who contributed to this research...." (p. 175). Because Pendery et al. have never described in the scientific literature how they located and gathered data from subjects, it is impossible to know what contributions Subject CD-E 1 made to their investigation that warranted the acknowledgment. However, in a “To whom it may concern" letter, dated March 16, 1981, Pendery wrote the following about Subject CD-E 1: "After working with [subject's name] for these many months, it is difficult for me to imagine how the project could have been completed without him. $\mathrm{He}$ not only was able to locate and coordinate former research subjects, and had their confidence, but turned out to have a genuine talent for research" (Miller et al., 1982).

The Dickens Committee's evaluation of Subject CD-E 1's affidavit was enlightening. We were able to provide evidence of multiple important inaccuracies in the affidavit and also in statements attributed to Subject CD-E 1 by the media. The totality of evidence was summarized by the Dickens Committee as "casting the gravest doubts upon the reliability of his affidavit and unsworn statements upon which Pendery et al. appear to have relied" (Dickens et al., 1982, p. 104).

The following few examples illustrate how our evidence contradicts Subject CD-E 1's recollections:

1. In his sworn affidavit this subject alleges that after September 1971, he "left the area [where he had been living] and had no contact of any kind with the Sobells until January 1974." Our evidence of contacts with him after September 1971 include a tape recorded interview conducted in June 1972. It was readily apparent this tape was authentic, since the subject's voice and manner of speaking were clearly the same as he presented himself in his multiple media appearances that occurred around the time of the Dickens Committee investigation.

2. Our research records contained two handwritten letters (including their postmarked envelopes) sent to us by the subject in March and April 1972.

3. The subject had stated to the media that none of his relatives were ever contacted by us. Yet, in one of the letters he sent to us, he wrote "[his wife's name] told me you called, but she lost the phone number."

4. Although this subject was quoted in several media reports as saying that he had never or only on a few occasions been interviewed for follow-up, our records, as reviewed by the Dickens Committee, documented that we had contacted him for follow-up on 28 occasions (Dickens et al., 1982, p. 78).

5. He alleged that a member of the clinical staff of the hospital had interviewed him for the study and had at one point counseled him not to withdraw from the study. That former staff member was located and submitted a statement to the Dickens Committee attesting that the subject's statements were untrue.

These examples constitute just part of the evidence used to challenge Subject CD-E 1's recollections and his affidavit, but they are quite sufficient to make the point that the subject's statements were replete with errors.

Now, in Maltzman's present article, we are exposed to selected portions of a second subject's affidavit (Subject O.L.). The reason we have chosen to respond to the allegations concerning O.L. is to demonstrate that Maltzman was correct when he declared the value of his retrospective verbal reports by subjects to be a "tempest in a teapot."

With regard to the excerpts Maltzman presents from O.L.'s affidavit (dated April 7, 1982), the following observations are drawn from our research records collected during the period 1970-72. Particularly useful is an interview we conducted and tape recorded with O.L. on July 14, 1972 (this was shortly after the end of his second year of follow-up; such tape-recorded interviews were conducted with subjects after their 2-year followup data had been collected; see Sobell and Sobell, 1976).

Point 1: One of O.L.'s statements as presented by Maltzman was that O.L. had never "had the kind of withdrawal symptoms which require medical care." Presumably, the inclusion of this statement is intended to question whether the subject was truly dependent on alcohol. In our tape-recorded interview with the subject, when he was asked whether the time of day when he drinks had changed as compared to before treatment, he responded: "Well, yes. Normally now it's in the evening time. I don't. It used to be I'd wake up and I'd have to have a belt to straighten me out and get me in shape to go to work. And now, I can get up and feel real good. No problem."

Point 2: O.L. states that he was not interviewed for follow-up by anyone other than Linda Sobell. Our records, however, indicate that he was interviewed on three occasions by the research project social worker whose interview notes were handwritten (this former staff member provided a handwriting sample to the Dickens Committee). 
Point 3: O.L. states that he was drunk on approximately $25 \%$ of the days during the follow-up period. In our publications he was reported as having been drinking heavily or incarcerated for approximately $13 \%$ of the days during the first year of follow-up. With regard to the second year of follow-up, the following exchange occurs in the interview:

Q: "Looking at your last year you have only had three isolated days like that where you have been, you know, let's say really snockered. Is that an improvement over the 2 years prior to your going to the hospital?"

O.L.: "Oh, you better believe it. Does [sic] the birds fly through the trees?"

Point 4: Somewhat consistent with his affidavit, O.L. did reflect a highly ambivalent attitude toward controlled drinking. When asked about the desirability of a controlled drinking treatment goal, he responded: "Well, I'll tell you. If you want a real answer to that, I'd just as soon never take another drop of liquor in my life. Now this is a very serious answer, because I don't think it [pause] well, I don't know, once in a great while, but I don't think it does a person any good."

Later in the interview, when asked to comment about being able to drink as part of the treatment, he expressed a stronger opinion: "To take a person like me who has been an alcoholic for quite a few years and to go in and start on one or two or three. It won't work. It just won't work."

This led the interviewer to question him again about his earlier drinking report:

Q: "But you are doing controlled drinking now, though?"

O.L.: "Yes."

Point 5: Finally, it is notable that about 5 weeks after the tape-recorded interview, O.L. voluntarily called to inform us that he had changed jobs, was living in a trailer in the same city where he had been staying with his aunt and had a new telephone number.

These five examples demonstrate that we have ample records, retained for nearly 20 years, to support the results we reported. With regard to our reported treatment outcome findings, the crux of Maltzman's objections appears to us as, indeed, a "tempest in a teapot."

\section{Randomization}

Maltzman presents the case of Subject J.Z. as an example of "apparent reassignment" of a subject from the experimental to the control group. He fails to mention that this specific allegation was investigated by the Dickens Committee (Dickens et al., 1982, see pp.
62-63). This and other allegations of nonrandom assignment are discussed at some length in the Dickens Committee report (Dickens et al., 1982), by ourselves (Sobell and Sobell, 1984a,b) and by Baker's comment in this issue of the Journal.

In the case of J.Z., while it is unclear what might have occurred, the Dickens Committee noted that there was substantial evidence that the hospital records contained numerous errors (Dickens et al., 1982, pp. 62-64), of which this entry might have been such an occasion. More likely, the subject could have been used by other hospital staff in an experimental session that was unrelated to the IBTA study. As noted by Baker elsewhere in this issue, other hospital staff did occasionally use the bar facility, sometimes without our knowledge or approval. Two points are pertinent to this possibility. First, the hospital record apparently indicates that the subject participated in a "Research Special project," the only use of that nomenclature (i.e., the word "special") of which we are aware. Second, since J.Z. was among the very first subjects to enter the study, if he had been assigned to the experimental group he would have begun the experimental intoxication phase of the study within the few days following assignment. Yet, the supposed drinking session cited by Maltzman is reported to have occurred nearly 2 months after J.Z.'s entry into the IBTA study. It is inconceivable that he would have been run in an IBTA session 2 months after entering the study, when several other, later assigned, subjects had already completed the procedures, as any attempted reassignment would have been obvious to the research staff. All of the former IBTA research staff who were involved in the random assignment procedure filed a statement or affidavit with the Dickens Committee attesting that assignment was always random (Dickens et al., 1982, see pp. 57-66 for excerpts from some of these statements). In fact, Maltzman must be aware of these statements, as his present article refers to our major rejoinder to Pendery et al. (Sobell and Sobell, 1984b) wherein there appear excerpts of statements by former IBTA staff regarding the randomization procedures.

Finally, the following portion of the tape-recorded interview conducted with Subject J.Z. on July 17, 1972, subsequent to the end of his second year of follow-up, is relevant. This interview occurred years before we were to become aware of Maltzman's allegations about randomization. We also assume this is the only case where a drinking session by a control subject is alleged to have occurred, since Maltzman had access to the hospital records and it is reasonable to assume that he would have called any similar case to our attention.

Q: “One last question here. [Note: the following question was asked of all control subjects in the IBTA study 
during the tape-recorded interview conducted at the end of their 2-year follow-up.] How do you feel about not being included in the actual research treatment program even though we accepted you, but the coin tossed you into the control group. That is, we didn't run you through the specific research program. Would you have liked to have gone through it? The total ..."

J.Z.: "You're talking about social, make a social?"

Q: "Yeah, with the videotapes and everything."

J.Z.: "Yeah, I would have liked that."

Q: "O.K."

J.Z.: “I, I did feel a little bit, you know, um, well . . ."

Q: "Left out?"

J.Z.: “I, I did feel a little bit let down. I'll be, that's honestly what I felt."

Q: “O.K."

J.Z.: "I wanted very much to be in that."

Before concluding this section, we feel that the following point is long overdue. Of all of Maltzman's allegations, we have long been perplexed at his steadfast insistence that subjects were not randomly assigned. If our evidence only consisted of our verbal reports that subjects were not reassigned, then it would be our word against Maltzman's. However, we have more than that. As noted previously, all five staff members involved in the randomization of subjects provided statements or affidavits to the Dickens Committee (see above). These statements were provided a decade after the study, and were independently drafted. All of the staff members' statements support the fact that we did what we said we did-subjects were randomly assigned, and group assignments did not change. To understand how utterly incredible Maltzman's allegation is, readers need only to appreciate the way the study was performed: (1) several staff members were always present and witnessed the coin flip at the staff meetings where subjects were randomly assigned; (2) immediately after the meeting the assignment was noted in the subject's research record by one of the staff; (3) a master list of subjects, their group assignment, and a research session checklist were posted for the duration of the study in the central research office where research records were kept; (4) after each session for each subject, the staff member who ran the session had to make a note in the subject's research record; and (5) during the first follow-up year, research staff conducted follow-ups and wrote relevant notes in the subject's research record. Thus, a change of groups anywhere during the course of the study would have been obvious. Put differently, nonrandomization and reassignment would have been impossible without the knowledge of some or all of the research staff. Thus, Maltzman's allegation regard- ing randomization calls into question the integrity of the entire staff of the IBTA project, none of whom ever gained from the publication of the study. (Note: In this issue one of the former IBTA staff members responds to Maltzman's article; see Baker, pp. 481-483.) Readers, as with any jury, must judge the evidence for themselves. We offer that the truth lies in the weight of the evidence, which is why we have been vindicated in all five inquiries.

\section{Is Science Self-Correcting?}

The following excerpt is taken from an article on the findings of the ADAMHA investigation that was published in the U.S. Journal of Drug and Alcohol Dependence: "Is it a dead issue? 'It isn't dead because I'm not dead,' Maltzman says"' (Worden, 1984, p. 11). We do not understand Maltzman's beliefs, but we recognize his entitlement to them, and that his actions may be guided by them. At some level, we all have beliefs that guide our actions. One of our beliefs is that reasonable people, presented with reasonable evidence, will come to reasonable conclusions. This is demonstrated by the fact that we have been vindicated in five separate investigations.

The controversy over the IBTA study has continued for far too long. Moreover, it now lacks relevance for the so-called controlled drinking controversy, as an abundance of recent studies have made clear that the issue of moderation outcomes cannot be ignored (see Sobell and Sobell, 1987, for a review). In the end, as with all scientific disputes, this issue will be settled by the weight of the evidence.

Unlike Maltzman, we have no intention of continuing to battle over the IBTA study. We simply do not intend to spend any more of our lives responding to or dignifying inane attacks. The multiple investigations, our previous responses and this present article make it clear that we have abundant material to call upon in our defense. We anticipate that our calling a halt to this controversy will be welcomed by most who have followed the drawn-out debate.

There is a final statement of importance, however, and it is relevant to Maltzman's concern that science be self-correcting. In 1988 the following editorial statement was published by Science, the journal that in 1982 published Pendery et al.'s attack on our work: "The scientific apparatus cannot afford to disregard accusations of fraud, and competent whistle-blowers help science. Investigations should be pursued meticulously, but the final report should strongly state the outcome: If the accusation is correct the miscreant should be punished and the whistle-blower commended. If, however, the accusation is incorrect, in addition to the usual bland announcement of exoneration there should 
be a denunciation of the false charges and a documentation of the time, anguish, and delay that has been occasioned. Science cannot tolerate fraud, but it should not be at the mercy of headline-happy journalists or incompetent whistle-blowers" (Koshland, 1988, p. 585).

\section{Acknowledgment}

We greatly appreciate comments made by a small group of colleagues on an earlier version of this response.

\section{Notes}

1. Letter to M. and L. Sobell from D. Mills, American Psychological Association Ethics Committee, March 4, 1985.

2. "Notice of ruling sustaining demurrer without leave to amend; order and judgment of dismissal thereon." James Doyle Carroll et al. vs. State of California et al., Case No. 236924, Superior Court of California, County of San Bernardino, December 30, 1987.

\section{References}

Cook, D.R. Craftsman versus professional: Analysis of the controlled drinking controversy. J. Stud. Alcohol 46: 433-442, 1985.

Cooper, A.M., Sobell, M.B., Maisto, S.A. and Sobell, L.C. Criterion intervals for pretreatment drinking measures in treatment evaluation. J. Stud. Alcohol 41: 1186-1195, 1980.

DiCKens, B.M., DOOB, A.N., WarWick, O.H. AND WineGard, W.C. Report of the Committee of Enquiry into Allegations Concerning Drs. Linda and Mark Sobell, Toronto: Addiction Research Foundation, 1982.

DooB, A.N. Understanding the nature of investigations into alleged fraud in alcohol research: A reply to Walker \& Roach. Brit. J. Addict. 79: 169-174, 1984.

FisHer, K. Challenge to Sobell work will have broad impact says review group chief. The Journal (Addiction Research Foundation, Toronto), August 1982, pp. 1, 3 .

FisHER, K. Congress leaves Sobell probe in Health Department's hands. APA Monitor, August 1983, p. 48.
Koshrand, D.E., JR. Science, journalism, and whistle-blowing. Science 240: 585, 1988.

Maisto, S.A., Sobell, M.B., Cooper, A.M. ANd Sobell, L.C. Testretest reliability of retrospective self-reports in three populations of alcohol abusers. J. Behav. Assess. 1: 315-326, 1979.

MeACham, A. Sobells continue to try out moderation therapies. U.S. J. Drug Alcohol Depend. February 1989, p. 10.

Miller, R.C., McShane, P.A. and the Alcoholism Trust ComMITTEE. Alcoholic's Heaven, Carlsbad, Calif.: S.O.B.E.R. Foundation and the Alcoholism Trust Committee, 1982.

Pendery, M.L., Maltzman, I.M. AND West, L.J. Controlled drinking by alcoholics? New findings and a reevaluation of a major affirmative study. Science 217: 169-175, 1982.

Sobell, L.C., Maisto, S.A., Sobell, M.B. and Cooper, A.M. Reliability of alcohol abusers' self-reports of drinking behavior. Behav. Res. Ther. 17: 157-160, 1979.

Sobell, M.B. AND Sobell, L.C. Alcoholics treated by individualized behavior therapy: One year treatment outcome. Behav. Res. Ther. 11: 599-618, 1973.

Sobell, M.B. AND Sobell, L.C. Second year treatment outcome of alcoholics treated by individualized behavior therapy: Results. Behav. Res. Ther. 14: 195-215, 1976.

Sobell, M.B. AND Sobell, L.C. Behavioral Treatment of Alcohol Problems: Individualized Therapy and Controlled Drinking, New York: Plenum Press, 1978.

Sobell, M.B. AND Sobell, L.C. Under the microscope yet again: A commentary on Walker and Roach's critique of the Dickens Committee's enquiry into our research. Brit. J. Addict. 79: 157-168, 1984a.

Sobell, M.B. AND SoBelL, L.C. The aftermath of heresy: A response to Pendery et al.'s (1982) critique of "Individualized behavior therapy for alcoholics." Behav. Res. Ther. 22: 413-440, 1984b.

Sobell, M.B. and Sobell, L.C. More on Maltzman. Bull. Soc. Psychologists Addict. Behav. 3: 74-76, 1984c.

Sobelt, M.B. AND Sobelt, L.C. Conceptual issues regarding goals in the treatment of alcohol problems. Drug soc. 1 (No. 2/3): 1-37, 1987.

Trachtenberg, R.L. Report of the Steering Group to the Administrator Alcohol, Drug Abuse, and Mental Health Administration Regarding Its Attempts to Investigate Allegations of Scientific Misconduct Concerning Drs. Mark and Linda Sobell, Rockville, Md.: Alcohol, Drug Abuse, and Mental Health Administration, 1984.

WORDEN, M. ADAMHA's Sobell investigation inconclusive. U.S. J. Drug Alcohol Depend., October, 1984, pp. 1, 11. 